\title{
A ORGANIZAÇ̃̃O DAS NAÇÕES UNIDAS E SUAS LÍNGUAS: UM DISCURSO DA EXCLUSÃO?
}

\section{MARCOS VINÍCIUS SANTOS DE CARVALHO TERRA; DANTIELLI ASSUMPÇÃO GARCIA; LUCÍLIA MARIA ABRAHÃO E SOUSA}

\author{
Faculdade de Filosofia, Ciências e Letras de Ribeirão Preto \\ Universidade de São Paulo \\ Av. Bandeirantes, 3900 - 14040-901 - Monte Alegre - Ribeirão Preto - SP - Brasil \\ marcos_vsctehotmail.com ; dantielligarcia@gmail.com ; \\ luciliamasousa@gmail.com
}

\begin{abstract}
Resumo. Este estudo aborda a noção de ideologia, sob a perspectiva teórica da Análise de Discurso de linha francesa; explana o surgimento da ONU e seus principais objetivos e denuncia a limitação linguística da Organização, a qual, atualmente, trabalha com seis línguas oficiais: inglês, chinês, francês, espanhol, russo e árabe. Além disso, com o objetivo de perceber como os efeitos de sentido se manifestam nos dizeres da ONU, foram feitas análises da página do UNRIC (Centro Regional de Informação das Nações Unidas) na Internet, de uma postagem da ONU na rede social Facebook e de alguns comentários de internautas a essa postagem. Inferimos que falar de língua nesse lugar, qual seja, de uma organização mundial com voz de autoridade, implica refletir sobre o discurso e as formas de legitimação da ideologia.

Palavras-chave: ONU; discurso; ideologia; línguas oficiais.
\end{abstract}

\begin{abstract}
This study addresses the notion of ideology, from the theoretical perspective of French Discourse Analysis; it explains the emergence of the UN and its main objectives, and denounces the linguistic limitations of the Organization, which currently works with six official languages: English, Chinese, French, Spanish, Russian and Arabic. In addition, aiming at understanding how the effects of meaning are manifested in sayings from UN, some analyzes of UNRIC (United Nations Regional Information Centre) Internet page were carried out, as well as some analyzes of a post from UN on Facebook social network and some comments from netizens to such a post. We infer that speaking of languages in this environment, namely, a worldwide organization with authority's voice implies reflecting both on the discourse and the forms of legitimizing ideology.
\end{abstract}

Keywords: UN; discourse; ideology; official languages.

\section{Dizeres iniciais: a ONU e as línguas}

Neste trabalho, sob a perspectiva teórica da Análise de Discurso pecheutiana, mobilizando a noção de ideologia, tal como trabalhada por Pêcheux ([1975] 1997), analisaremos a página inicial do UNRIC (Centro Regional de Informação das Nações Unidas), uma postagem da ONU na rede social Facebook e mais alguns comentários de internautas a essa postagem, com o objetivo de perceber como os discursos da ONU fazem funcionar dizeres, seriam de exclusão e discriminação?, ao impor um saber sobre as línguas que fazem ou não parte dessa instituição. Nosso texto se sustenta em três 
momentos. Inicialmente, faremos uma discussão sobre a ONU, mostrando como essa instituição surge e quais são seus objetivos. Essa discussão justifica-se por buscar compreender como a ONU sustenta um discurso de proteção e de intervenção na sociedade internacional e constitui um espaço de representatividade de diferentes nações unidas. Na continuidade, discorremos sobre o modo como a Análise de Discurso operacionaliza a noção de ideologia, com o intuito de analisar como certos sentidos acerca das línguas são estabilizados nos discursos da ONU. Por fim, faremos uma análise, da página do UNRIC, da postagem da ONU no Facebook da instituição, bem como de alguns comentários de usuários da rede a essa publicação.

\section{Organização das Nações Unidas: um dizer sobre a instituição}

Um breve dizer sobre a criação da ONU é importante para analisarmos a questão das línguas nesse espaço institucional de enunciação e analisarmos o funcionamento da ideologia como um mecanismo de produção/sustentação de sentidos dados às línguas nesse espaço internacional das Nações Unidas.

A Organização das Nações Unidas foi criada, sustentada em um discurso da inclusão de diferentes países da sociedade internacional e como protetora e amiga desses países, oficialmente, em 24 de outubro de 1945, uma vez que a comunidade internacional buscava uma forma de evitar novas tragédias como a II Guerra Mundial. Vale lembrar que:

[...] embora se associe naturalmente a ONU à manutenção da paz e da segurança internacionais, os seus objectivos, enunciados no artigo primeiro da Carta, são amplos e abrangentes o suficiente para não excluírem nenhuma área de intervenção na sociedade internacional, entre a cooperação económica, social, política, militar, humanitária, cultural ou técnico-científica. (XAVIER, 2007, p. 30)

O nome Nações Unidas foi dado pelo presidente estadunidense Franklin Roosevelt, sendo utilizado pela primeira vez em 12 de janeiro de 1942, durante a Declaração das Nações Unidas, que reunia representantes de vários países, os quais assumiram o compromisso de manter a luta contra as potências do Eixo, isto é, contra Alemanha, Itália e Japão. Em Londres, no ano de 1946, ficou estabelecido que a sede permanente da organização seria nos Estados Unidos. Hoje, a ONU possui sedes em Genebra (Suíça), Viena (Áustria) e Nairóbi (Quênia), embora, a sede central permaneça em Nova York. Os propósitos da ONU foram assim definidos pelos países-membros:

manter a paz e a segurança internacionais; Desenvolver relações amistosas entre as nações; Realizar a cooperação internacional para resolver os problemas mundiais de caráter econômico, social, cultural e humanitário, promovendo o respeito aos direitos humanos e às liberdades fundamentais; Ser um centro destinado a harmonizar a ação dos povos para a consecução desses objetivos comuns. (UNIC RIO, (C2014) 
A ONU, desde sua criação, conta com uma atuação bastante significativa dos Estados Unidos. Trata-se do país que abriga os principais órgãos da instituição. E mais, é o seu maior fiador. O orçamento regular da ONU é feito por todos os EstadosMembros da organização de acordo com a riqueza e o desenvolvimento de cada nação. A organização conta com seis órgãos principais: a Assembleia Geral, o Conselho de Segurança, o Conselho Econômico e Social, o Conselho de Tutela, a Corte Internacional de Justiça e o Secretariado. O Secretariado possui como suas principais tarefas:

administrar as forças de paz; Analisar problemas econômicos e sociais; Preparar relatórios sobre meio ambiente ou direitos humanos; Sensibilizar a opinião pública internacional sobre o trabalho da ONU; Organizar conferências internacionais; Traduzir todos os documentos oficiais da ONU nas seis línguas oficiais da Organização. (UNIC RIO, (C2014)

O Departamento de Informação Pública (DPI), pertencente ao Secretariado, foi criado em 1946, por uma resolução da Assembleia Geral, a fim de promover a conscientização e compreensão das atividades da ONU, utilizando como instrumentos de divulgação meios como o rádio, a televisão, a imprensa e a Internet. Os Centros de Informação das Nações Unidas (United Nations Information Centres - UNICs) fazem parte do Departamento de Informação Pública (Department of Public Information - DPI) da ONU. O Departamento visa à divulgação dos trabalhos da organização, contribuindo, assim, com "a paz mundial" e com o desenvolvimento de povos do mundo inteiro. Além disso, fornece produtos e serviços informacionais, com a proposta de facilitar o trabalho e atividades dos Estados-Membros, funcionários e pesquisadores. Também oferece auxílio na comunicação interna da Organização das Nações Unidas e conduz a uma maior participação e envolvimento no trabalho da ONU, por meio de palestras, exposições, conferências, publicações e materiais de ensino.

Os UNICs foram criados, como ficou decidido na Assembleia Geral, de 13 de fevereiro de 1946, com o objetivo de que as atividades da ONU fossem conhecidas na língua das regiões onde os Centros estão presentes (UNIC RIO, C2014). Eles oferecem informações a respeito de assuntos econômicos, políticos e sociais. Além disso, os centros promovem seminários e discussões sobre diversos temas relevantes. Atualmente, existem 63 UNICs divididos nos cinco continentes. Tais centros alcançam mídias e instituições educacionais; desenvolvem parcerias com governos, organizações da sociedade civil local e setor privado, além de manter bibliotecas e fontes de informação eletrônicas. Eles estão divididos em cinco regiões: 1. África, 2. Américas, 3. Estados Árabes, 4. Ásia e Pacífico, 5. Europa e Comunidade dos Estados Independentes.

Neste trabalho, a partir de leituras da Análise do Discurso pecheutiana e de seus desdobramentos no Brasil, analisaremos os discursos sobre as línguas da Organização das Nações Unidas, organização na qual diferentes línguas têm um papel de destaque nas relações de poder. Para tanto, analisaremos a página inicial do UNRIC de língua portuguesa, a postagem na página do Facebook da ONU: "a ONU seleciona jovens de até 32 anos para iniciar carreira internacional" e mais alguns comentários de internautas a essa postagem. Nosso intuito é analisar como a ONU formula um dizer, naturalizado pelo funcionamento da ideologia, sobre as línguas que fazem parte ou não da instituição, sustentando uma diferenciação entre línguas francas (de trabalho) e línguas oficiais, e um 
imaginário de instituição igualitária em que a exclusão não entra em suas relações entre países e povos.

\title{
2. A Análise de Discurso e a ideologia: um mecanismo de produção de evidências
}

Fundada na década de sessenta por Michel Pêcheux na França, a Análise do Discurso se apresenta neste trabalho como referencial teórico para análise dos dizeres oficiais da ONU. Sabe-se que não existe neutralidade discursiva, mesmo em situações aparentemente simples. Logo, não há a possibilidade de que os discursos oficiais das Nações Unidas tenham um caráter neutro, estando isentos de um funcionamento ideológico em que dizeres e sentidos estão em confronto.

A teoria criada por Pêcheux permite analisar como certos sentidos estão em circulação e outros são opacificados nos discursos oficiais da ONU, produzindo seus efeitos na chamada sociedade da informação. A Análise de Discurso possibilita também a compreensão de como as relações de poder são simbolizadas na organização e transmitidas para as mais diversas comunidades. Desse modo, compreender, aqui, é "saber como um objeto simbólico (enunciado, texto, pintura, música etc.) produz sentidos" (ORLANDI, 2007, p.26) e que esses sentidos sempre podem ser outros.

Definir "ideologia”, conceito mobilizado para essa análise, não é uma tarefa tão simples, pelo contrário, trata-se de um trabalho que exige um posicionamento. Isso ocorre devido a várias concepções que a palavra assume em diferentes correntes teóricas. Muitos autores trabalham com o conceito, o qual muda, de acordo com o momento histórico e político, e assume novos significados:

\begin{abstract}
"Ideologia" pode designar qualquer coisa, desde uma atitude contemplativa que desconhece sua dependência em relação à realidade social, até um conjunto de crenças voltado para a ação; desde o meio essencial em que os indivíduos vivenciam suas relações com uma estrutura social até as ideias falsas que legitimam um poder político dominante. Ela parece surgir, exatamente, quando tentamos evitá-la e deixa de aparecer onde claramente se esperaria que existisse. (ZIZEK, 1996, p. 9)
\end{abstract}

A linguagem constitui o sujeito, por isso, a ideologia deve ser tratada nos atos concretos da linguagem, isto é, na materialidade. Na ótica do funcionamento da linguagem, a ideologia se materializa no discurso. Pêcheux, ao teorizar ideologia na Análise de Discurso, retoma as teses de Louis Althusser para o qual "a ideologia passa então a ser o sistema das ideias, das representações, que domina o espírito de um homem ou de um grupo social" (ALTHUSSER, 1980, p. 69). Como ressalta Zizek (1996, p. 17),

também convém mencionar aqui Michel Pêcheux, que deu um toque estritamente linguístico à teoria da interpelação de Althusser. Seu trabalho centra-se nos mecanismos discursivos que geram a "evidência" do Sentido. Ou seja, um dos estratagemas fundamentais da ideologia é 
a referência a alguma evidência - "Olhe, você pode ver por si mesmo como são as coisas!" ou "Deixe os fatos falarem por si" talvez constituam a arqui-afirmação da ideologia - considerando-se, justamente, que os fatos nunca "falam por si", mas são sempre levados a falar por uma rede de mecanismos discursivos.

Na Análise do Discurso, é mister sublinhar o ideológico e o histórico. A ideologia faz do indivíduo sujeito, o qual estará inserido numa determinada formação social. "Na ideologia, o que é representado não é o sistema das relações reais que governam a existência dos indivíduos, mas a relação imaginária destes indivíduos com as relações reais em que vivem" (ALTHUSSER, 1980, p.82). O indivíduo toma caminhos, os quais são determinados pelo contexto social e pela manifestação ideológica de um período. É importante ressaltar que isso acontece, em muitos casos, de modo inconsciente.

O entendimento da forma como o discurso funciona possibilita a compreensão do que acontece na sociedade e, também, com o sujeito. A Análise do Discurso aborda uma materialidade dupla: da língua (estrutura) e da história (acontecimento). "A ideologia, por sua vez, não é vista aqui como conjunto de representações nem como ocultação da realidade. Enquanto prática significante, discursiva, ela aparece como efeito da relação necessária do sujeito com a língua e com a história, para que signifique" (ORLANDI, 1996, p. 28).

Com nossa análise de dizeres da ONU sobre as línguas, questionamos algumas evidências ("estratagema fundamental da ideologia") que sustentam a instituição como um lugar de grande diversidade e representatividade dos povos. A construção da naturalização dos sentidos se dá através da ideologia, processo que faz parecer evidente que se diga apenas de um modo, apagando outras formas de enunciar que ali poderiam irromper.

Ao trabalharmos analiticamente discursos da ONU sobre as línguas da instituição, consideramos a língua "no acontecimento do significar, na relação de homens com homens, sujeitos e sujeitos" (ORLANDI, 2007, p. 13). A partir desse posicionamento, trabalhamos a língua não como algo individual e abstrato, mas em seu funcionamento, em suas relações entre sujeitos, sociedade, ideologia e história. Ao analisarmos os discursos da ONU sobre as línguas que fazem parte da instituição, buscamos mostrar como seus dizeres estão imaginariamente sustentados por um dizer historicamente constituído que coloca a ONU como representante de diferentes países em que a exclusão e a desigualdade não entram nos muros institucionais, como buscamos mostrar na primeira parte desse trabalho. Há pelo funcionamento da ideologia uma naturalização dos sentidos da ONU como uma instituição que representa e protege diferentes países do mundo de modo mais humanitário e igualitário possível.

Portanto, a ideologia funciona como um mecanismo de evidenciação de sentidos. O efeito ideológico consiste em tornar os sentidos fixos, necessários, a-históricos. Nossa proposta neste artigo é, assim, questionar os discursos da ONU em relação às línguas da instituição, analisando como se estabilizam sentidos à instituição que a colocam como representante de diferentes nações unidas, mas que, por meio da escolha de seis línguas oficiais, acaba por excluir, ao mesmo tempo, diferentes nações que diz representar. Ao mobilizarmos a noção de ideologia neste trabalho, pretendemos mostrar como os sentidos 
não são previamente dados, mas que se constituem nas relações entre sujeito, história e ideologia.

Para a Análise de Discurso, por fim, os sentidos não existem em si, mas são determinados pelas posições ideológicas colocadas em jogo no processo sócio-histórico em que são produzidos. Ao analisarmos os discursos da ONU, temos um enunciador que fala da posição da instituição que representa as diferentes nações do mundo. Dessa posição de uma instituição que representa diferentes nações, funcionando como memória um dizer da ONU como uma instituição em que todos estão protegidos e representados, algo não dito funciona e faz reverberar sentidos, os quais tentamos agora flagrar.

\section{As línguas na ONU: que dizer é este?}

As línguas, de acordo com Guimarães (2003), em seu funcionamento, são afetadas por condições históricas específicas. Para o autor,

as línguas funcionam segundo o modo de distribuição para seus falantes. Ou seja, línguas não são objetos abstratos que um conjunto de pessoas em algum momento decide usar. Ao contrário, são objetos históricos e estão sempre relacionadas inseparavelmente daqueles que as falam. Não há língua portuguesa, sem falantes desta língua, e não é possível pensar a existência de pessoas sem saber que elas falam tal língua e de tal modo. É por isso que as línguas são elementos fortes no processo de identificação social dos grupos humanos. O espaço de enunciação é que atribui as línguas para seus falantes. E cada espaço de enunciação tem uma regulação específica, ou seja, distribui as línguas em relação de um modo particular. (GUIMARÃES, 2003, p. 47-48)

Podemos pensar a ONU como um espaço de enunciação em que há uma regulação específica das línguas que funcionarão na instituição e que seus membros falarão. Como "forte elemento de identificação social", as línguas na ONU funcionam sustentadas por relações históricas e de poder que marcam as diversas relações da ONU com os países que ela representa.

Guimarães (2003) considera algumas categorias ao refletir sobre essa distribuição das línguas para seus falantes:

Língua materna: é a língua cujos falantes a praticam pelo fato de a sociedade em que se nasce a praticar; nesta medida ela é, em geral, a língua que se representa como primeira para seus falantes. Língua Franca: é aquela que é praticada por grupos de falantes de línguas maternas diferentes, e que são falantes desta língua para o intercurso comum. Língua nacional: é a língua de um povo, enquanto língua que o caracteriza, que dá a seus falantes uma relação de pertencimento a este povo. Língua oficial: é a língua de um Estado, aquela que é obrigatória nas ações formais do Estado, nos seus atos legais. Pode-se ver que as duas primeiras categorias tratam das relações cotidianas entre 
falantes e as duas seguintes de suas relações imaginárias (ideológicas) e institucionais. (GUIMARÃES, 2003, p. 48; grifos do autor)

$\mathrm{Na}$ ONU, não vemos o funcionamento de diferentes línguas nacionais que marcam o pertencimento dos povos que essa instituição representa. Há somente o funcionamento de línguas francas para o intercurso comum entre os membros da Organização, e das línguas oficiais.

A Organização das Nações Unidas, atualmente, trabalha com seis línguas oficiais: inglês, chinês, francês, espanhol, russo e árabe. Sabe-se que língua é uma poderosa ferramenta de transmissão cultural. A ONU, que tem como missão, como diz em seus discursos, combater as discrepâncias existentes entre as nações, utiliza um sistema com um número muito reduzido de idiomas oficiais, uma vez que representa 193 países. Uma organização, com o porte das Nações Unidas, não poderia ter, talvez, apenas seis línguas oficiais, pois uma das principais marcas do imperialismo é impor o idioma das grandes potências. Para que uma pessoa exerça um cargo na ONU, por exemplo, ela precisa dominar pelo menos um dos idiomas oficiais, como se pode observar no tex to encontrado no site do UNIC do Rio de Janeiro:

devido à própria essência da missão das Nações Unidas, podem se candidatar para trabalhar na Organização especialistas de diversas áreas como medicina, direito, jornalismo, relações internacionais ou comunicação, somente para citar uns poucos exemplos. Porém, dois denominadores são comuns a todos os cargos nas Nações Unidas: o domínio de algum dos idiomas oficiais da ONU - inglês, francês, espanhol, chinês, árabe ou russo - e, na maioria dos casos, possuir um diploma universitário. (UNIC RIO, (C2014)

Há, de certo modo, um discurso de "imposição linguística/idiomática", o qual acaba por excluir profissionais que não dominam essas línguas oficiais, mas que falam as línguas de países que fazem parte da ONU. A imposição linguística/idiomática estaria relacionada talvez com a exploração econômica e com a dominação política. Além disso, a valorização de um idioma em relação a outro provoca a potencialização das desigualdades sociais, ou seja, as Nações Unidas, nesse aspecto, estão indo contra seus objetivos e discursos de igualdade, constituindo-se, assim, como uma instituição que exclui os sujeitos.

Na página do UNRIC de língua portuguesa, isso também pode ser notado, embora, nela, aparentemente, não só as seis línguas estejam representadas. O Centro Regional de Informação das Nações Unidas (UNRIC), alocado em Bruxelas, atende os seguintes países da Europa Ocidental: Andorra, Alemanha, Bélgica, Chipre, Dinamarca, Espanha, Finlândia, França, Grécia, Irlanda, Islândia, Itália, Luxemburgo, Malta, Mônaco, Noruega, Países Baixos, Portugal, Reino Unido, Santa Sé, S. Marino e Suécia. O Centro Regional substituiu os Centros de Informação sediados em nove cidades europeias (Atenas, Bonn, Bruxelas, Copenhaga, Lisboa, Londres, Madrid, Paris e Roma), de acordo com uma decisão tomada pela Assembleia Geral da ONU (UNRIC, C2013). Nesse site do UNRIC, apresenta-se a ferramenta "A ONU na sua língua", que possibilita o uso de 13 línguas da região europeia atendida pelo centro de informação. Os idiomas disponíveis são: alemão, dinamarquês, espanhol, finlandês, francês, grego, inglês, islandês, italiano, neerlandês, norueguês, português e sueco. 


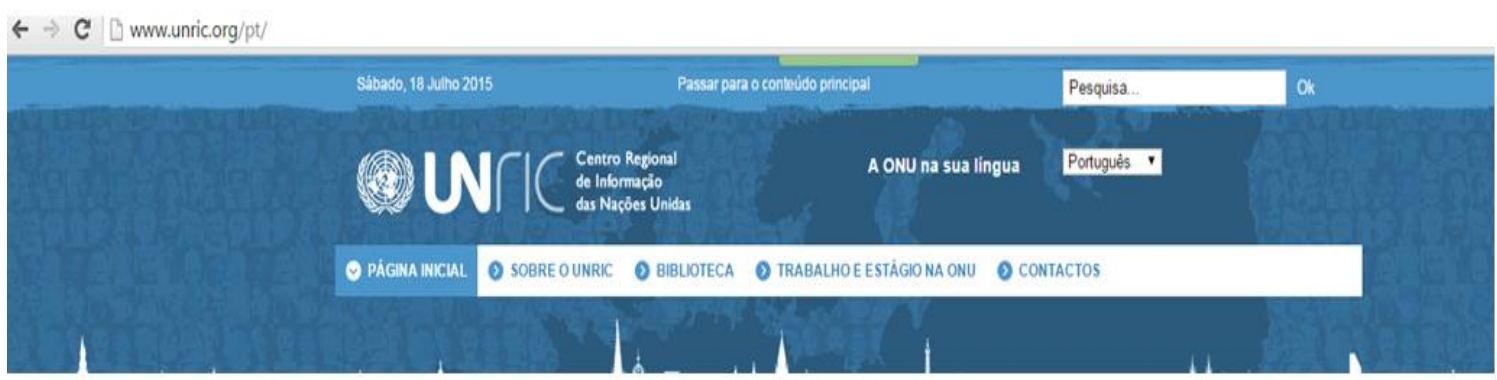

Figura 1: A ONU na sua língua

Ao clicarmos em uma dessas línguas, a página do UNRIC é traduzida para essas línguas.

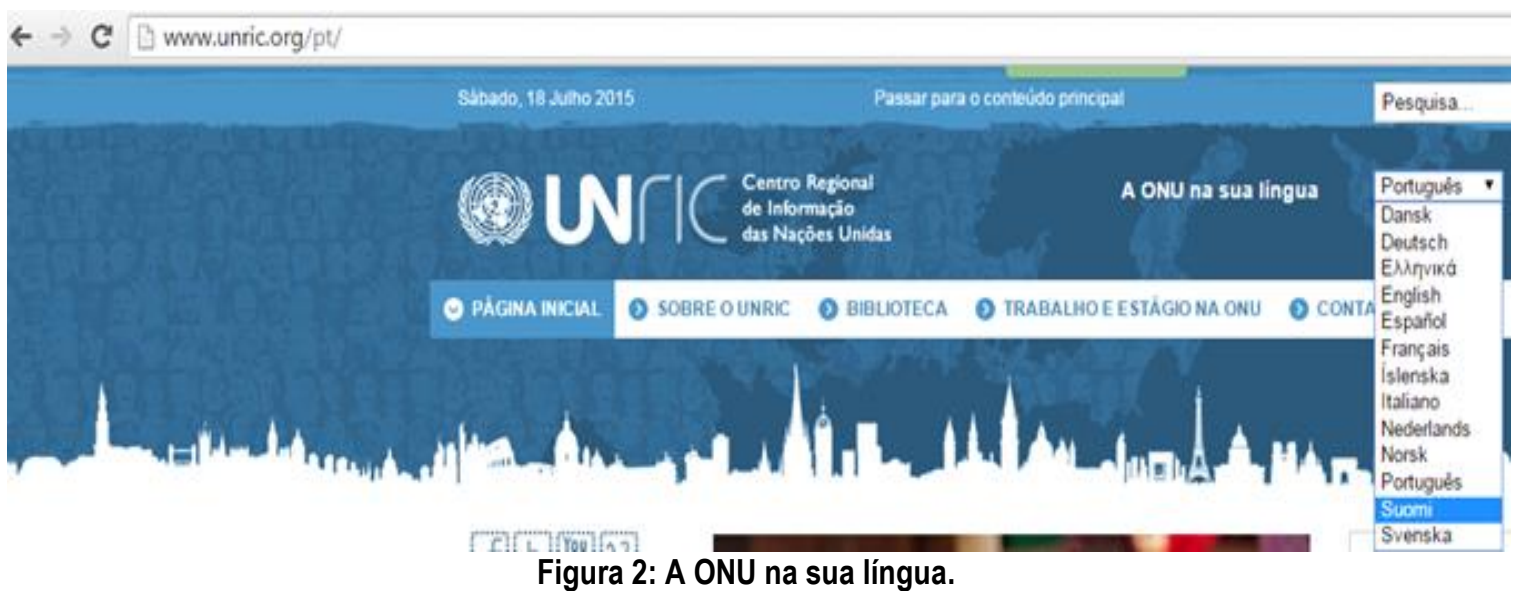

O Centro possui uma biblioteca que, embora contenha materiais de informação em outras línguas da Europa Ocidental, apresenta documentos e publicações das Nações Unidas em apenas três idiomas: inglês, francês e espanhol. As três línguas são utilizadas por serem as únicas da região atendida pelo UNRIC que fazem parte das línguas oficiais. O objetivo do Centro é informar os europeus e envolvê-los em assuntos de interesse global. Países que não falam pelo menos uma das seis línguas oficiais não contam com a tradução de muitos documentos oficiais das Nações Unidas, desse modo, impossibilitase a esses sujeitos o acesso à instituição que diz representá-los. Mais uma vez vemos uma imposição linguística/idiomática da ONU. Essa imposição marca como as relações de poder são fortes nessa instituição. Questões linguísticas facilmente se refletem em questões ligadas ao poder político, econômico e militar. $\mathrm{O}$ fato da documentação produzida pelas Nações Unidas ser produzida em apenas seis línguas oficiais provoca uma opressão linguística em povos que não utilizam nenhuma delas:

O capitalismo contemporâneo, por seu lado, compreendeu que tinha interesse em quebrar as estátuas. Dominação mais sutil, que consiste em reforçar as marcas pelo jogo interno de sua diferença, pelo logro publicitário da linguagem comercial e política: "a língua de vento" permite à classe no poder exercer sua maestria, sem mestre aparente. Ela não serve tampouco a seu mestre. O imperialismo fala hoje uma 
língua de ferro, mas aprendeu a torná-la tão ligeira quanto o vento. (GADET; PÊCHEUX, 2004, p. 24)

Assim acreditamos funcionar a ONU. Ao impor as seis línguas ("línguas de vento"), aos 193 países, exerce o poder com maestria. Com línguas e mãos de ferro, silencia países, embora, aparentemente, represente-os. Gostaríamos de pontuar que cada uma das seis línguas oficiais das Nações Unidas possui um dia próprio para celebração. Os dias foram estabelecidos pelo Departamento de Informação Pública da ONU em 2010 com a finalidade de comemorar a diversidade cultural, promover a equidade entre os idiomas oficiais e celebrar o multilinguismo. No dia de cada língua, acontecem exposições, palestras, apresentações folclóricas, exibições de filmes e outras atividades culturais em torno da língua celebrada (UNITED NATIONS, @2015). Além disso, cada língua oficial possui um site no qual se fala um pouco sobre essa língua.

Em 20 de março, na mesma data do Dia Internacional da Francofonia, é comemorado o Dia da Língua Francesa. Segundo a ONU, trinta e oito países entre os 193 Estados-membros utilizam o Francês para se corresponderem com a Organização (UNITED NATIONS, (O2015). Diferentemente do chinês, cuja comemoração é feita no dia 20 de abril. Uma data dedicada a Tsang-kie, fundador da escrita chinesa, uma das línguas mais antigas do mundo e, atualmente, a mais falada. A Língua Árabe, por sua vez, tem seu dia celebrado em 18 de dezembro, data referente à inclusão do Árabe como língua oficial da ONU. O Árabe é um dos idiomas mais populares do planeta, falada por mais de 422 milhões de pessoas (UNITED NATIONS, (C2015). No dia 23 de abril, data de aniversário de morte de William Shakespeare, comemora-se o Dia da Língua Inglesa. O Inglês é a língua mais utilizada na sede da ONU.

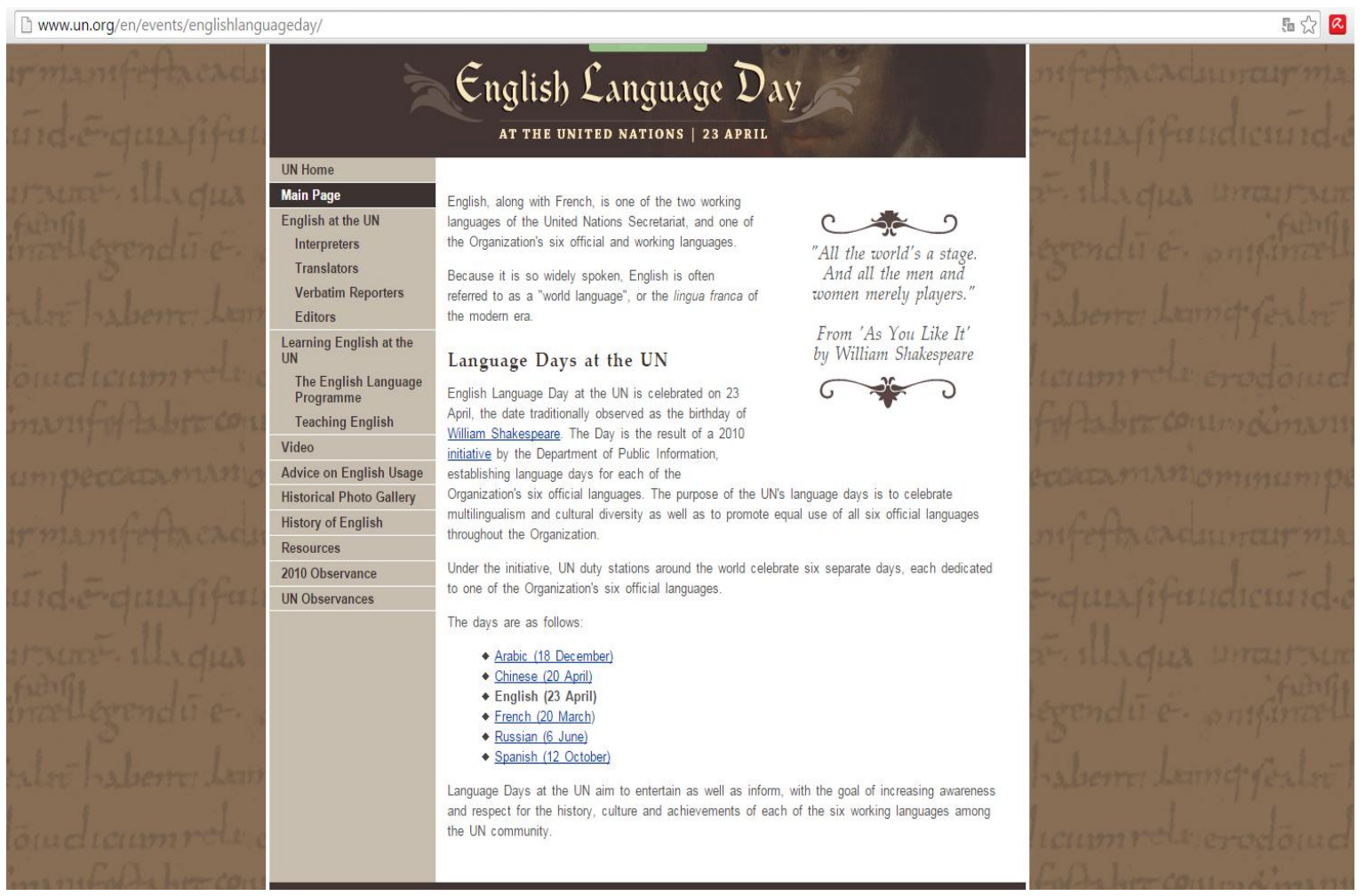

Figura 3: English Language Day. 
Em 6 de junho, data de comemoração do aniversário de Alexander Pushkin, celebra-se a Língua Russa. O Russo é o idioma oficial da Federação da Rússia, o maior país do mundo (17.075.200 quilômetros quadrados), com uma população de 143 milhões de pessoas (UNITED NATIONS, (C2006). Comemora-se, na ONU, no dia 12 de outubro o dia do Espanhol, mesma data em que é celebrado o Dia da Hispanidade. O Espanhol é a língua, no atual momento, de 21 Estados-Membros da Organização das Nações Unidas (UNITED NATIONS, (2015). Aparentemente, a escolha pelos idiomas oficiais pela ONU faz-se em virtude ou do maior número de falantes, ou em virtude do maior país, ou porque mais países-membros se comunicam naquela língua. Há uma forte presença de um discurso estatístico que busca legitimar, numericamente, essa escolha pela organização. Não vemos, por exemplo, nenhuma língua africana. As relações da ONU se dão por essa escolha linguística entre os continentes europeu, asiático, americano. $\mathrm{O}$ continente africano, pelo menos linguisticamente, não é representado na instituição, nem o Brasil, uma vez que o português também não é uma língua oficial.

A ONU, também, oferece cursos nas seis línguas oficiais, através do United Nations Language and Communications Programme. Os cursos são ministrados por professores que possuem, no mínimo, um mestrado em Linguística Aplicada (ou áreas afins) e com pelo menos cinco anos de experiência de ensino. Esses cursos são para os funcionários terem a oportunidade de aprender os idiomas oficiais da Organização e aumentar a sua capacidade de desempenhar as suas funções profissionais com maior competência linguística (UNITED NATIONS, @2006). Um estranhamento se produz aqui, uma vez que, para ser admitido na ONU é necessário falar fluentemente um dos idiomas oficiais, o curso seria, então, para aprimorar uma competência linguística que os profissionais da ONU já possuem? Questionamos-nos.

É importante ressaltar que quatro das seis línguas oficiais da ONU, isto é, Inglês, Francês, Russo e Chinês, pertencem a países com poder de veto no Conselho de Segurança. Isso mostra como as questões linguísticas marcam as relações de poder entre os países:

O Conselho de Segurança é o órgão da ONU responsável pela paz e segurança internacionais. Ele é formado por 15 membros: cinco permanentes, que possuem o direito a veto - Estados Unidos, Rússia, Grã-Bretanha, França e China - e dez membros não-permanentes, eleitos pela Assembleia Geral por dois anos. Este é o único órgão da ONU que tem poder decisório, isto é, todos os membros das Nações Unidas devem aceitar e cumprir as decisões do Conselho. (UNIC, (C)2014)

$\mathrm{Na}$ continuidade de nosso artigo, gostaríamos de analisar uma postagem da ONU no Facebook ${ }^{1}$, a qual oferece uma oportunidade de trabalho na ONU. Na postagem "ONU seleciona jovens de até 32 anos para iniciar carreira internacional", a questão linguística também é colocada. Para candidatar-se a uma vaga, os jovens devem "ter fluência em inglês ou francês". Além de serem duas línguas oficiais da ONU, como vimos, são as únicas línguas de trabalho da instituição. O inglês na instituição é visto como uma "língua

\footnotetext{
${ }^{1}$ CENTRO DE INFORMAÇÃO DAS NAÇÕES UNIDAS PARA O BRASIL. ONU seleciona jovens de até 32 anos para iniciar carreira internacional. Disponível $\mathrm{em}$ https://www.facebook.com/UNICRiodeJaneiro/?fref=ts; acesso em jul. 2015.
} 
franca" da era moderna. Uma língua franca é a língua tomada como comum de grupos sociais que falam, cada um, uma língua diferente dos outros. Como coloca Guimarães²:

há uma diferença importante entre uma língua franca e uma língua oficial. A diferença está em que a língua oficial é dada como a língua do Estado de modo que todos que a ele estão ligados são obrigatoriamente falantes dela. Mesmo que certas pessoas não a falem, no plano oficial são tomados imaginariamente como seus falantes e são tratados como tal, são cobrados por isso. A língua franca não tem essa obrigatoriedade. Ela, em verdade, funciona como garantia das relações entre falantes de línguas diversas, sem que tenham que abandonar suas línguas para estarem em relação. No entanto, em muitos casos na história das relações entre as línguas, uma língua que se instala como língua oficial assume para os falantes das outras línguas o papel de língua franca, estabelecendo assim, com frequência, uma hierarquia de valores das línguas. Esta hierarquia opera contra as demais assim como pode discriminar seus falantes.

A ONU faz circular sentidos ao inglês e francês, impondo essas línguas aos outros países que fazem parte da instituição. Acreditamos haver uma hierarquia entre as línguas na ONU com a imposição de seis línguas oficias (que podemos ver não são oficiais em diversos países membros da ONU) e de duas línguas de trabalho (inglês e francês). Há, de certa forma, na instituição a discriminação dos falantes que a ONU "representa" e "protege".

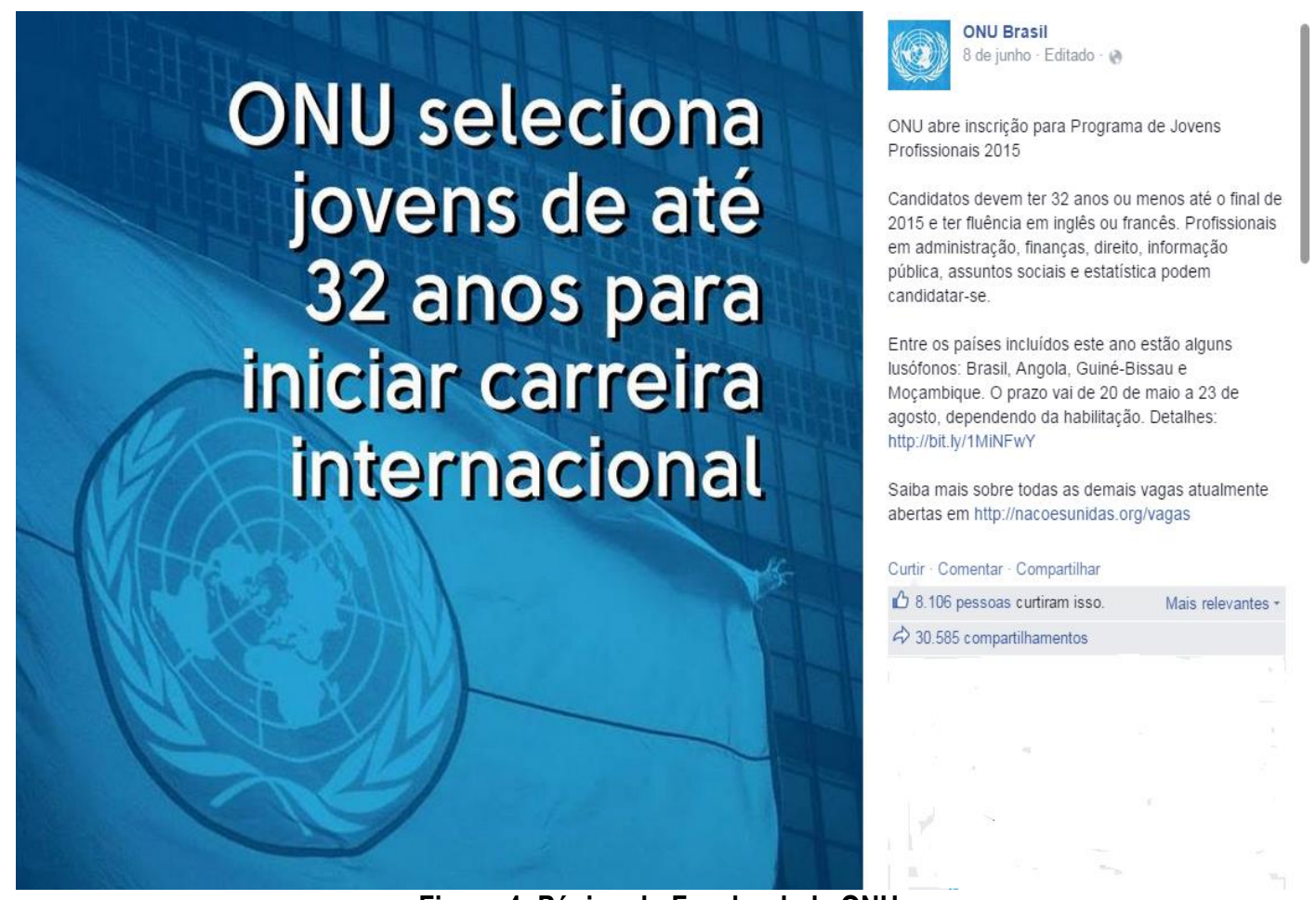

Figura 4: Página do Facebook da ONU.

\footnotetext{
${ }^{2}$ GUIMARÃES, Eduardo. Conceitos Linguísticos: Língua Franca. Em: Enciclopédia de Línguas no Brasil. Disponível em http://www.labeurb.unicamp.br/elb/portugues/leiamais_lingua_franca.html; LABEURB, NUDECRI, UNICAMP, Campinas; acesso em jan. 2016.
} 
Mesmo países lusófonos (Brasil, Angola, Guiné-Bissau e Moçambique) apresentando vagas para diferentes profissionais, a língua portuguesa não é contemplada, já que não faz parte das línguas oficiais, nem das línguas de trabalho. Essa vaga também reduz a somente dois dos idiomas oficiais contemplados. De certa maneira, essa imposição linguística contradiz até um dizer da ONU, salientado no início deste artigo, o qual colocava que candidatos a vagas na instituição deveriam dominar um dos idiomas oficiais e não somente as línguas de trabalho. Os comentários dos usuários do Facebook questionam também essa obrigatoriedade linguística. Podemos ver por esses dizeres o questionamento dessa naturalização ideológica dos sentidos:

C1: E essa discriminação com quem não fala inglês ou francês? Disso ninguém vai reclamar? (Comentário irônico, caso alguém não entenda)

C2: Sem falar nessa artimanha de trabalhar como consultor pra não precisar assinar a carteira da galera, né? Você fica anos trabalhando na ONU e sai com uma mão na frente e a outra atrás porque nem transporte e alimentação eles te dão. Além, claro, dessa obrigatoriedade em falar três línguas fluentemente. As vezes pra trabalhar em favela.

Os usuários da rede veem essa imposição linguística/idiomática como uma discriminação linguística, questionando, entre outras coisas, a ONU como uma instituição em que a igualdade e a representação dos diferentes membros e países é tão (i)legítima. Não há, pela ONU, a obrigatoriedade em falar três línguas diferentes, mas sim uma das duas línguas de trabalho e uma das línguas oficiais. O usuário da rede coloca uma observação questionando essa obrigatoriedade de saber diferentes línguas para trabalhar "em favela". Questionamo-nos: o espaço da favela não seria legitimado para as exigências, não seria um lugar em que as línguas francesa e inglesa seriam faladas? Há, aqui, acreditamos, uma diferença entre saber uma língua para fazer parte do quadro da ONU e falar uma língua no espaço em que a ONU atuará. A imagem que a instituição busca criar para seus profissionais é a de um sujeito que tem amplo domínio linguístico, seja de uma língua oficial, seja de uma língua de trabalho, seja da língua que será falada na favela.

Os usuários do Facebook buscam dialogar com a ONU com o intuito de entender por que dessa escolha:

C3: Olá ONU Brasil, boa noite! Gostaria de saber a justificativa das vagas em projetos sempre terem a fluência em inglês ou francês. Por que outras línguas não entram no escopo, como por exemplo, o espanhol, ja que estamos situados na América Latina? Acredito que há uma demanda muito grande de pessoas interessadas nos programas porém que não possuem estas línguas com fluência. Agradeço a atenção e a resposta. Abraços!

Esse comentário tem as seguintes respostas. Uma de um usuário do Facebook e outro da própria $\mathrm{ONU}^{3}$ :

\footnotetext{
${ }^{3}$ Omitimos os nomes dos sujeitos para preservar suas identidades.
} 
R1: Porque são as duas línguas oficiais da ONU (sim existem outras línguas oficiais como o russo, chinês etc, mas essas duas são as primordiais)

R4: ONU Brasil Oi XXX, incentivamos você a buscar vagas nos diversos escritórios pela América Latina que a ONU possui, e no qual o espanhol é solicitado. O espanhol é um idioma oficial das Nações Unidas mas, como lembrou YYYY, o inglês e o francês são os idiomas de trabalho, de fato. As vagas em nosso site são apenas para o Brasil e, assim, em outros sites do sistema ONU você terá mais chances de encontrar a vaga ideal. Alguns escritórios que cobrem o nosso país estão em outros países, falantes do espanhol, como é o caso do ACNUDH, que se localiza em Santiago. Att. Equipe ONU Brasil.

A resposta da ONU não salienta o porquê dessa escolha, todavia, aponta para o estabelecimento de uma diferença. Temos idiomas oficiais e idiomas de trabalho. Os idiomas de trabalho são o inglês e o francês. Línguas de ferro que têm longa história de legitimação imposta, seja pela moda ou pela força.

Para concluir, buscamos mostrar com essas análises como um dizer sobre as línguas se faz presente na ONU. As escolhas das línguas oficiais e de trabalho mostram como as relações entre as grandes potências que fazem parte da instituição se dão. Embora diga representar centena de países-membros, pela imposição linguística de línguas oficiais, que não são línguas impostas pelos Estados dos diferentes países-membros da ONU, essa representação passa por uma subordinação linguística que acaba por silenciar diversos falares de países que sustentam também o discurso da ONU.

\section{Considerações Finais}

Neste trabalho, ao iniciarmos com um breve dizer sobre a criação da ONU, explicitamos como a instituição sustenta-se como um espaço de proteção e representação de diferentes países do mundo. Com a discussão acerca da ideologia e com as análises, salientamos como há uma naturalização dos sentidos sobre a ONU, os quais acabam por falhar e escapar, mostrando como a instituição é um lugar discriminatório quando pensamos as línguas. Ao impor seis línguas oficiais e duas de trabalho, a ONU discrimina falantes e age com mãos de ferro, limitando o espaço institucional de enunciação e fazendo circular um discurso de exclusão das nações unidas que estão, às vezes, distantes pelas imposições linguísticas/idiomáticas que funcionam tão fortemente na ONU.

\section{Referências bibliográficas}

ALTHUSSER, Louis. Ideologia e aparelhos ideológicos de Estado. Trad. Port. $3^{\text {a }}$. ed. Lisboa: Editorial Presença, 1980.

CENTRO DE INFORMAÇÃO DAS NAÇÕES UNIDAS PARA O BRASIL. ONU 
seleciona jovens de até 32 anos para iniciar carreira internacional. Disponível em https://www.facebook.com/UNICRiodeJaneiro/?fref=ts; acesso em jul. 2015.

GADET, Françoise; PÊCHEUX, Michel. A língua inatingível: o discurso na história da linguística. Trad. Bras. Campinas, SP: Pontes, 2004.

GUIMARÃES, Eduardo Roberto Junqueira. Conceitos Linguísticos: Língua Franca. Em: Enciclopédia de Línguas no Brasil. Disponível em http://www.labeurb.unicamp.br/elb/portugues/leiamais_lingua_franca.html; LABEURB, NUDECRI, UNICAMP, Campinas (SP); acesso em jan. 2016. dez. 2003

Enunciação e política de línguas no Brasil. Letras, Santa Maria, n. 27, pp. 47-53,

HUMANA GLOBAL. A Organização das Nações Unidas. Em: XAVIER, A. I. ONU: Organização das Nações Unidas. Humana Global, 2007. p. 9-174. Disponível em http://www.dhnet.org.br/abc/onu/onu_humana_global_onu.pdf; acesso em nov. 2013.

ORLANDI, E. P. Análise de Discurso: princípios e procedimentos. $7^{\mathrm{a}}$ ed. Campinas, SP: Pontes, 2007.

Exterioridade e ideologia. Cadernos de Estudos Linguísticos, Campinas (SP), n. 30, pp. 27-33, jan./jun. 1996.

PÊCHEUX, Michel. Semântica e discurso: uma crítica à afirmação do óbvio. Trad. Bras. $2^{a}$ ed. Campinas, SP: Editora da Unicamp, 1997.

UNIC RIO. Conheça a ONU. Rio de Janeiro, C2014. Disponível em http://unicrio.org.br/conheca-a-onu/; acesso em jul. de 2015.

. Faça parte da ONU. Rio de Janeiro, (C2014. Disponível em http://unicrio.org.br/faca-parte-da-onu/trabalho/; acesso em ago. 2014.

UNRIC. Sobre o UNRIC. Bruxelas, (2013. Disponível em http://www.unric.org/pt/sobre-o-unric; acesso em jul. 2015.

UNITED NATIONS. Department of Public Information. UN Web Services Section, () 2011. Disponível em http://www.un.org/en/hq/dpi/; acesso em ago. 2014.

UNITED NATIONS. Official Languages. UNITED NATIONS, C2015. Disponível em http://www.un.org/en/sections/about-un/official-languages/; acesso em jul. 2015.

UNITED NATIONS. UN Russian Language Programme. UNITED NATIONS, (C)2006. Disponível em http://www.un.org/depts/OHRM/sds/lcp/Russian/; acesso em jul. 2015.

UNITED NATIONS INFORMATION CENTRES. UNIC. Information Centres Service, C2008. Disponível em https://unic.un.org/; acesso em ago. 2014. 
UNITED NATIONS. United Nations Language and Communications Programme. United Nations, C2006. Disponível em http://www.un.org/depts/OHRM/sds/lcp/UNLCP/english/about.html;.acesso em jul. 2015.

ZIZEK, S. O espectro da ideologia. Em: (Org.). Um mapa da ideologia. Rio de Janeiro: Contraponto, 1996.

Para citar este texto:

GARCIA, Dantielli Assumpção; ABRAHÃO E SOUSA, Lucilia Maria; TERRA, Marcos Vinícius Santos de Carvalho. A Organização das Nações Unidas e suas línguas: um discurso da exclusão? Entremeios [Revista de Estudos do Discurso], Seção Estudos, Programa de Pós-graduação em Ciências da Linguagem (PPGCL), Universidade do Vale do Sapucaí, Pouso Alegre (MG), vol. 12, p. 11-25, jan. - jun. 2016.

DOI: http://dx.doi.org/10.20337/ISSN2179-3514revistaENTREMEIOSvol12pagina11a25 